\title{
VISÕES DA LIBERDADE: REPUBLICANISMO E LIBERALISMO NO DEBATE TEÓRICO CONTEMPORÂNEO \\ Ricardo Silva
}

No curso das décadas recentes, podemos observar, tanto na historiografia do pensamento político como nos debates da teoria política contemporânea de corte analítico e normativo, duas grandes ondas de orientação republicana contestadoras do domínio ideológico liberal. A primeira onda tomou forma no trabalho de historiadores do humanismo cívico e, subsequentemente, nas elaborações de teóricos comunitaristas. Entre as décadas de 1950 e 1990, autores como Hannah Arendt, Hans Baron, J. G. A. Pocock, Alasdair MacIntyre, Charles Taylor e Michael Sandel, para mencionar alguns dos mais conhecidos, reivindicavam os valores da virtude cívica e da participação na vida comunitária como antídotos ao individualismo "atomista" da vertente dominante do pensamento liberal. A partir de meados da década de 1990, o debate entre comunitaristas e liberais entra em refluxo; e, embora a crítica comunitarista tenha alterado em alguma medida a face do liberalismo, a percepção geral que parece ter restado do debate é a do caráter excessivamente exigente das demandas feitas em nome da comunidade no contexto de sociedades caracterizadas pelo "fato do pluralismo." 
A segunda onda republicana começa a se esboçar ao longo da década de 1980, adquirindo uma forma mais definida em meados dos anos de 1990. Associados a ela encontram-se autores como Quentin Skinner, Philip Pettit, Maurizio Viroli, John Maynor, entre outros. Ao mesmo tempo que procuram se afastar do modo como humanistas cívicos e comunitaristas apresentam suas críticas ao liberalismo, esses autores continuam a sustentar que o republicanismo deve ser entendido como um movimento de contestação à hegemonia da tradição liberal, porém mais bem equipado do que o comunitarismo para lidar com os desafios de uma ordem social caracterizada pela irreconciliável diversidade de concepções do bem.

Este artigo destina-se ao exame das disputas correntes entre republicanos e liberais, concentrando-se nas questões trazidas ao debate pelos defensores da segunda onda neorrepublicana na teoria política contemporânea. Con182 siderando que os autores representativos dessa vertente argumentam que o republicanismo moderno tem sua gênese na antiga República romana, utilizo a expressão "republicanismo neorromano" para referir-me às suas formulações. Não é difícil perceber que o conceito de liberdade encontra-se no núcleo das disputas conceituais e retóricas entre republicanismo neorromano e liberalismo. Por isso, minha reconstrução e análise do debate concentrar-se-á no que representantes de ambas as correntes têm a dizer sobre o referido conceito.

O debate entre republicanos e liberais tem ocorrido de modo igualmente intenso em dois planos de investigação distintos mas interconectados: o da história do pensamento político e o da teoria política analítico-normativa. Ou seja, ao mesmo tempo que reivindicam a especificidade de uma longa tradição de pensamento político e constitucional, tanto neorromanos como liberais procuram apresentar os elementos definidores de uma visão de liberdade alegada- 
mente apta a responder aos dilemas econômicos, institucionais e éticos das sociedades contemporâneas. São dois registros de uma mesma controvérsia. Abordarei aqui as linhas gerais que conformam o debate nesses dois registros.

$\mathrm{Na}$ primeira parte do artigo, apresento de maneira sucinta a atual disputa entre republicanismo neorromano e liberalismo no plano da historiografia das ideias. Há, de fato, uma tradição republicana organizada em torno de uma visão da liberdade alternativa à visão liberal dominante? Os teóricos neorromanos acreditam que sim. Após indicar os argumentos que sustentam essa crença, indico as dúvidas levantadas por alguns historiadores das ideias sobre a adequação da narrativa dos neorromanos. A discussão no plano da história das ideias é inconclusiva e está intimamente relacionada ao debate analítico-normativo sobre o conceito de liberdade na teoria política contemporânea. As disputas sobre a evolução histórica do republicanismo em sua relação com a tradição liberal são indissociáveis da controvérsia, também inconclusiva, sobre o conceito de liberdade no âmbito da teoria política contemporânea.

A segunda parte do artigo dedica-se ao exame dos desdobramentos mais recentes desse debate teórico no plano analítico-normativo. Inicialmente apresento os contornos da concepção liberal de liberdade negativa. Noto que essa concepção se impôs, no pós-Segunda Guerra, sobre outra vertente do liberalismo, que, entre a segunda metade do século XIX e primeira metade do século XX, absorveu a influência de uma visão positiva da liberdade. Em seguida, aponto as críticas dos neorromanos à liberdade negativa do liberalismo, bem como suas propostas de reelaboração da concepção negativa da liberdade por meio do critério da "ausência de dominação". Na sequência, devolvo a palavra aos liberais, expondo as reações mais recentes dos teóricos da chamada "liberdade negativa pura" à alternativa formulada pelos republicanos. Concluo examinando os argu- 
mentos com quais os teóricos neorromanos têm procurado responder aos ataques dessa vertente "neo-hobbesiana" do liberalismo contemporâneo.

Antes de passar ao exame da disputa entre republicanismo neorromano e liberalismo, devo concluir esta introdução com uma nota metodológica a respeito da natureza da minha abordagem do tema em pauta. Por que abordar o tema da liberdade por intermédio da reconstrução de um debate? A resposta para isso encontra-se no fato de que o conceito de liberdade, como os outros conceitos-chave da teoria política, pertence a uma classe de conceitos que o filósofo Walter Gallie, em texto seminal de 1956, denominou "conceitos essencialmente contestados". Nas palavras de Gallie (1956, p. 193),

[...] o reconhecimento de um dado conceito como essencialmente contestado implica o reconhecimento

184 de seus usos rivais (tais como aqueles que o próprio usuário repudia) como não apenas logicamente possível e humanamente 'provável', mas também como algo de potencial valor crítico permanente para o uso ou interpretação do conceito em questão ${ }^{1}$.

Em outras palavras, os conceitos essencialmente contestados são construções refratárias a definições consensuais. A estabilização do significado semântico do conceito só acontece de maneira precária e contingente, até que uma perspectiva rival de definição do mesmo conceito desafie a definição previamente estabelecida. Não se trata apenas de reconhecer que cada perspectiva pode usar o conceito de modo distinto. É necessário também ter em conta que cada perspectiva reconhece que seu uso particular de determinado conceito é contestado por outras perspectivas, indu-

1 Todas as traduções de citações foram feitas pelo autor para este artigo. 
toras de usos alternativos, e que argumentar a favor de seus próprios critérios de utilização do conceito é também argumentar contra os critérios dos adversários. Ainda de acordo com Gallie (1956, p. 172): "Mais simplesmente, usar um conceito essencialmente contestado significa usá-lo contra outros usos e reconhecer que seu próprio uso do conceito tem de ser sustentado contra esses outros usos. Ainda mais simplesmente, usar um conceito essencialmente contestado significa usá-lo tanto agressiva como defensivamente".

Há um conjunto de critérios que nos permitem reconhecer o caráter essencialmente contestado de um conceito ${ }^{2}$. Destaco aqui que todo conceito desse tipo tem uma natureza avaliativa (ou normativa), na medida em que seu uso permite não apenas uma descrição de determinados estados do mundo, mas também, inevitavelmente, um julgamento, ou uma atribuição de valor aos estados do mundo descritos. Além disso, vale destacar que um conceito só se torna essencialmente contestado quando ele reflete o acúmulo de diferentes camadas de significado semântico nele sedimentadas no curso de um processo histórico. Compreender o caráter essencialmente contestado de um conceito é compreender a sua historicidade. Nietzsche (1998, p. 68) expressou com clareza esse ponto ao afirmar que "todos os conceitos em que um processo inteiro se condensa semioticamente se subtraem à definição; definível é apenas aquilo que não tem história”.

\section{Republicanismo e liberalismo no front historiográfico}

A emergência do neorrepublicanismo no debate teórico contemporâneo teve seu estímulo inicial no trabalho de historiadores das ideias, interessados em recuperar a linha de continuidade dessa tradição no pensamento político ocidental. Em meados da década de 1950, o historiador alemão Hans

\footnotetext{
2 Uma análise mais pormenorizada desses critérios, bem como de algumas das limitações da teoria de Gallie encontram-se em Silva (2013).
} 
Baron publicou a primeira edição de seu seminal Crisis of the early Italian Renaissance, em que se revelam as afinidades entre o humanismo cívico da Itália renascentista e a ideologia republicana que aflorava nas cidades-estados da península desde o final da Idade Média. Baron procura mostrar que os grandes teóricos do humanismo cívico italiano, a exemplo de Leonardo Bruni, revitalizaram a tradição republicana mediante recuperação do ideal da vida ativa, em um contexto em que as cidades italianas, diante da ameaça de expansão do poder dos príncipes, precisavam de uma ideologia capaz de fornecer a defesa de seu modo de vida livre e de sua política participativa e eletiva.

A obra de Baron exerceu forte influência na historiografia do Renascimento Italiano, inspirando o esforço mais amplo de reconstituição da história de toda a tradição republicana promovido por J. G A. Pocock em The machiavellian moment, obra de 1975. Pocock acentua as conexões, já visíveis na obra de Baron, entre o humanismo cívico da Itália 186 renascentista e os ideais atenienses de virtude cívica e liberdade. Deixando-se influenciar também pelo pensamento político de Hannah Arendt, Pocock apresenta o republicanismo como uma linguagem do ideário político articulada pelo ideal da liberdade positiva ${ }^{3}$. A contribuição de Pocock consiste não apenas em acentuar as origens aristotélicas do pensamento republicano do Renascimento italiano, mas também em compreender o legado do humanismo cívico em épocas posteriores, especialmente na cultura anglófona. Sua investigação compreende a recepção das ideias de Maquiavel

\footnotetext{
3 Conforme esclarece Pocock (1975, p. 550) na conclusão de sua obra-prima: "Em termos emprestados ou sugeridos pela linguagem de Hannah Arendt, este livro contou parte da história do Renascimento no Ocidente moderno do antigo ideal de homo politicus (o zoon politikon de Aristóteles), que afirma sua existência e sua virtude por meio da ação política”. Em outro texto, referindo-se aos republicanos do medievo tardio e do Renascimento, o autor reafirma essa visão: "[o] vocabulário republicano empregado por dictatores, retóricos e humanistas articulava a concepção positiva de liberdade: sustentava que o homo, o animale politicum, era constituído de tal forma que sua natureza só se completava em uma vita activa, praticada em um vivere civile" (Pocock, 2003, p. 87).
} 
no contexto do século XVII inglês e o modo pelo qual esse republicanismo inglês foi recepcionado no século XVIII na América, fomentando uma ideologia de grande impacto na luta pela fundação da República dos Estados Unidos. Não foi por acaso que o livro de Pocock exerceu tanta influência na historiografia recente da revolução norte-americana (cf. Rodgers, 1992). Pocock contribuiu para abalar a visão convencional da fundação da República como um movimento inspirado pelo liberalismo lockeano, visão que tem em Louis Hartz (1955) um de seus mais notáveis defensores. É verdade que a contribuição de Pocock pôde beneficiar-se dos caminhos abertos por autores como Bernard Bailyn (1967) e Gordon Wood (1969), cujos estudos sobre a revolução americana já enfatizavam a inspiração antes republicana do que liberal do movimento de ideias subjacente àquele processo revolucionário. Mas Pocock atribui uma força maior e um novo sentido às descobertas de Bailyn e Wood, na medida em que situa o republicanismo americano no interior de uma vasta tradição iniciada na Grécia de Aristóteles e adaptada ao mundo moderno por Maquiavel.

Não obstante a grande influência exercida pela narrativa de Pocock nos estudos históricos e constitucionais, a historiografia republicana vem, recentemente, experimentando outros caminhos. A principal contribuição nesse sentido tem sido realizada por Quentin Skinner, para quem o ressurgimento do republicanismo nos primórdios da modernidade deveu-se mais à recuperação de moralistas e historiadores romanos, como Cícero e Salústio, do que à retomada da concepção aristotélica das virtudes cívicas. É certo que, nos estudos de Baron e Pocock, autoridades romanas aparecem recorrentemente. Contudo, elas surgem como seguidoras da concepção aristotélica de cidadania. O que Skinner sustenta é que o republicanismo romano, embora não alheio à concepção grega de cidadania, deve ser pensado como uma tradição intelectual e política inde- 
pendente ${ }^{4}$. Se, na interpretação cívico-humanista, o centro das atenções era a noção de virtude cívica, na interpretação neorromana de Skinner, o foco da análise desloca-se para o conceito de liberdade pessoal.

Skinner questiona a tese de que a concepção republicana da liberdade teria sido retomada no Renascimento a partir da recuperação de Aristóteles. Ele também critica a visão de Baron de que o republicanismo teria emergido somente a partir do início do século XV, e que a ideologia da forma eletiva e participativa de governo teria surgido como uma resposta de Florença ao avanço das pretensões autocráticas e imperialistas do regime de Milão. Subjacente à tese de Baron, encontrar-se-ia a suposição de que o republicanismo moderno não teria sido possível sem o retorno aos antigos, especialmente a Aristóteles, cuja obra se tornara amplamente acessível em decorrência de traduções realizadas na virada do século XIV para o século XV na Itália. Já 188 em The foundations of modern political thought, publicado em 1978, Skinner chama a atenção para o fato de que muito antes de Aristóteles se tornar amplamente disponível para os humanistas dos séculos XIV e XV, os pré-humanistas já haviam descoberto uma maneira de defender as pretensões das cidades-repúblicas contra as tiranias. Assim, o historiador inglês antecipa em pelo menos dois séculos - de fins do século XIV, como queria Baron, para fins do século XII - a emergência do republicanismo no Regnum italicum. A justificação do regime eletivo e da participação cívica teria dispensado, no momento de sua emergência, o conhecimento da filosofia moral de Aristóteles. Embora não deixasse de se inspirar em fontes da Antiguidade, era em Roma, não na Grécia, que se encontrava a fonte de inspiração do republi-

\footnotetext{
4 Para uma crítica da visão de Skinner acerca da presumida autonomia das autoridades romanas, especialmente Salústio, em relação aos filósofos gregos, ver Walker (2006).
} 
canismo das cidades italianas. Tito Lívio, Salústio e, principalmente, Cícero teriam servido de modelos para os republicanos pré-humanistas. Com o senso de ironia que lhe é peculiar, Skinner sustenta que "foi dessas humildes origens, muito mais do que devido ao impacto do aristotelismo, que o republicanismo clássico de Maquiavel, Guicciardini, e de seus contemporâneos, descendeu originalmente". Assim, "a teoria política da Renascença, em todas as fases de sua história, deve muito mais profundamente a Roma do que a Grécia” (Skinner, 2002, p. 92).

Esse deslocamento de foco deu início a um prolongado esforço de investigação sobre a história do conceito de liberdade republicana. Sustentar a independência do republicanismo neorromano em relação à tradição aristotélica requer uma concepção de liberdade distinta daquela presente no modelo adotado por Pocock. Skinner procura refutar o enquadramento comunitarista vinculado ao modelo neoateniense, organizado em torno de uma visão enfaticamente positiva de liberdade. Isso explica porque em suas primeiras incursões no tema, o autor preferiu assumir uma posição polêmica, caracterizando a liberdade republicana como um tipo de liberdade negativa, uma liberdade desfrutada tanto por indivíduos como por coletividades para perseguirem os fins por eles próprios escolhidos. Conforme sustentava então,

[...] estar de posse da própria liberdade é ser livre no sentido "negativo" ordinário de não se estar constrangido por outros agentes. Portanto, ser livre é - como Maquiavel acrescenta com referência a agentes coletivos - agir "de acordo com a própria vontade e segundo o próprio juízo” (Skinner, 2002, p. 197).

Mas a fórmula apresentada por Skinner não tornaria a liberdade republicana idêntica à liberdade liberal? De modo a evitar tal conclusão, o historiador inglês ressalvava que as implicações dessa visão republicana da liberdade negativa 
são muito diferentes das encontradas na concepção liberal. O republicanismo não admitiria a realização da liberdade pessoal no contexto de uma comunidade não livre. Ou seja, sem liberdade política, não pode haver, de modo duradouro, liberdade individual. Daí a necessidade de os indivíduos participarem da vida política da República. Desse modo, Skinner afirma, contra o liberalismo, que a postulação de uma completa desvinculação entre liberdade individual e liberdade política representa uma grave "falha de racionalidade" (Skinner, 1984, p. 217). Seria como desejar os fins sem recorrer aos meios. Por outro lado, contra o comunitarismo, Skinner afirma que a participação política é precisamente um meio, um instrumento da liberdade, não a própria liberdade. Em relação à liberdade, a participação política seria um valor instrumental, não um valor intrínseco, como postulado no modelo aristotélico de republicanismo adotado por autores como Arendt, Pocock e por vários teóricos comunitaristas.

190 Por razões que observaremos adiante, Skinner abandona essa sua primeira formulação da liberdade republicana, uma vez que sua adoção implicava compreender o republicanismo como uma espécie de liberalismo em trajes participativistas. De todo modo, essa primeira fase da narrativa skinneriana sobre a liberdade republicana teve impacto tanto na historiografia das ideias como na teoria política normativa, constituindo a base para a reformulação do conceito de liberdade republicana, que passa a ser concebido como qualitativamente distinto da concepção liberal de liberdade negativa.

Embora sejam notáveis as divergências entre as narrativas de Pocock e Skinner, os dois principais protagonistas da chamada "Escola de Cambridge" confluem para uma conclusão comum quando o foco são as relações entre a tradição republicana e a tradição liberal. Tanto Pocock como Skinner e, depois deles, Philip Pettit, sustentam que essas duas tradições maiores do pensamento político ocidental representam visões rivais do conceito de liberdade e das formas institu- 
cionais que substancializam tal conceito. Se o republicanismo foi uma força intelectual dominante desde o Renascimento até as revoluções do século XVIII, seus ideais começam a entrar em declínio e a ser substituídos pelos ideais do liberalismo a partir da virada do século XVIII para o século XIX. O republicanismo torna-se então uma tradição periférica, enquanto, cada vez mais, o liberalismo assume o papel de força intelectual dominante no mundo contemporâneo.

É precisamente essa tese histórica sobre a rivalidade entre a tradição republicana e a liberal que vem sendo posta em dúvida em estudos mais recentes. Mesmo um teórico como Maurizio Viroli, alinhado ao republicanismo neorromano de Skinner e Pettit, rejeita a narrativa em que republicanismo e liberalismo aparecem como tradições inteiramente distintas, em rotas de colisão no curso da história moderna. Para Viroli, longe de surgir como um movimento intelectual alternativo ao republicanismo, o pensamento liberal surge, na verdade, como uma espécie de herdeiro problemático da tradição republicana. Assim, "de um ponto de vista histórico, a relação entre liberalismo e republicanismo é uma relação de derivação e inovação" (Viroli, 2002, p. 58). O liberalismo compartilha de uma série de princípios já presentes no republicanismo clássico, principalmente "a defesa do Estado limitado contra o Estado absolutista” (Viroli, 2002, p. 58). Além disso, contra as concepções comunitaristas da política, o liberalismo associa-se ao republicanismo na crença de que "o conflito social é tanto inevitável quanto realmente benéfico" à ordem social e política (Viroli, 2002, p. 59). No entanto, prossegue Viroli (2002, p. 61), "de um ponto de vista teórico, o liberalismo pode ser considerado um republicanismo empobrecido ou incoerente", uma vez que estaria menos preparado "para acomodar as demandas de liberdade como ausência de dependência, que são centrais ao ideal da liberdade civil”.

Recentemente, ao elaborarem uma narrativa até certo ponto próxima a de Maurizio Viroli, os politólogos Andreas 
Kalyvas e Ira Katznelson reforçaram a tese do parentesco histórico entre republicanismo e liberalismo. Para esses autores, é destituída de fundamento a crença adotada por autores como Pocock, Skinner e Pettit de que "o republicanismo e o liberalismo [...] emergiram de fontes particulares, um isolado do outro, como dois vocabulários 'incomensuráveis'”, e de que as relações entre as duas tradições representam um "jogo de soma zero", em que "a vitória de uma deve implicar a derrota da outra" (Kalyvas e Katznelson, 2008, p. 4).

A diferença essencial entre o relato de Kalyvas e Katznelson em relação ao relato de Viroli encontra-se na moral da história. Para Viroli, como vimos, o liberalismo, embora ainda mantendo um conjunto de ideais republicanos, pode ser compreendido como um "republicanismo empobrecido", na medida em que se afasta de princípios caros ao republicanismo clássico articulados em torno do ideal da liberdade como independência e não dominação. Para Kalyvas e Katznelson

192 ocorre justamente o contrário: o liberalismo consiste na atualização e aprimoramento da tradição republicana clássica, tornando-a apta para lidar com os desafios de uma sociedade comercial moderna. Assim, o liberalismo emergiria de um esforço dos próprios pensadores republicanos para livrarem-se dos aspectos anacrônicos da tradição republicana clássica. Da metamorfose do republicanismo clássico, motivada por sua necessidade de adaptação ao mundo moderno e efetivada ao longo do meio século que se estende de 1780 a 1830, ter-se-ia originado o liberalismo tal qual o conhecemos. Como resumem os autores,

[...] o liberalismo não é externo à história do republicanismo. [...] o liberalismo tal como o conhecemos nasceu do espírito do republicanismo, a partir de tentativas de adaptar o republicanismo às revoluções política, econômica e social do século XVIII e das primeiras décadas do século XIX (Kalyvas e Katznelson, 2008, p. 4). 
Para dar corpo à sua narrativa, Kalyvas e Katznelson promovem um exame detalhado dos textos de um conjunto pensadores que teriam enfrentado o dilema posto ao republicanismo clássico pela emergência da sociedade comercial. Adam Smith, Adam Ferguson, Thomas Paine, James Madison, Germaine de Staël e Benjamin Constant são os protagonistas dessa história do nascimento do liberalismo no interior da tradição republicana. Haveria um "projeto comum" ligando esses pensadores. Cruzando fronteiras nacionais, linguísticas e regionais, assim como fronteiras políticas e filosóficas, eles "compartilhavam um modo de pensar, raciocinar e imaginar a política para os tempos modernos" (Kalyvas e Katznelson, 2008, p. 176). Esse "projeto comum" estaria longe de representar uma ruptura definitiva com a tradição republicana clássica, como dão a entender os neorrepublicanos. Ao contrário, ele seria a única via aberta, nas condições das sociedades modernas, para a sobrevivência dos ideais republicanos.

Em face da dificuldade para se estabelecer a tese da radical rivalidade entre republicanismo e liberalismo, historiadores vinculados à perspectiva neorromana vêm alterando sutilmente os termos da disputa historiográfica, como se observa em trabalho recente de Eric MacGilvray (2011). Em vez de uma história da rivalidade entre liberdade republicana e liberdade liberal, ou entre liberdade positiva e liberdade negativa, MacGilvray relata uma história do embate entre a liberdade republicana, entendida como ausência de dominação, e a liberdade de mercado. Para o autor, a hipótese de uma relação de oposição e exterioridade entre republicanismo e liberalismo só se sustenta à custa de uma considerável simplificação e redução de escopo da tradição liberal. A lista de autores, desde fins do século XVIII até a atualidade, que poderiam compor um cânone de uma variante liberal do republicanismo (ou republicana do liberalismo) não é nada desprezível. Para MacGilvray, mais 
compreensiva é a hipótese de que "a relação histórica entre essas duas escolas de pensamento não é uma relação de conflito e supressão, mas sim de fertilização cruzada e de síntese" (MacGilvray, 2011, p. 57).

Se não há uma incompatibilidade genética entre a liberdade republicana e a liberdade liberal, o mesmo não pode ser dito da relação do republicanismo com a liberdade de mercado. O eclipse da tradição republicana é concomitante à afirmação das propaladas virtudes do mercado livre na organização da vida econômica e social moderna, virtudes, é verdade, ardorosamente defendidas pelo eixo dominante da tradição liberal. Mas a liberdade de mercado e o liberalismo econômico não recobrem todo o espectro do liberalismo. Ou seja, MacGilvray entende que a hipótese da concepção republicana de liberdade como instrumento de uma disputa ideológica requer que se defina com mais precisão o verdadeiro alvo do ataque dos neorrepublicanos. $\mathrm{O}$ 194 principal motivo de discórdia entre a liberdade republicana e a liberdade de mercado reside no fato de que "a política republicana almeja genuinamente o controle coletivo sobre os resultados sociais", enquanto "uma sociedade de mercado ideal é aquela em que os resultados sociais são tanto quanto possível determinados pelo próprio mercado", sendo este o "produto de um indefinido número de decisões baseadas no autointeresse de pessoas desconhecidas entre si e, portanto, não responsivas umas em relação às outras" (MacGilvray, 2011, p. 3).

Em suma, o debate historiográfico corrente sobre a relação entre as tradições republicana e liberal opõe duas narrativas principais. A primeira sustenta a hipótese da rivalidade entre as duas tradições, que se encontrariam no curso da história moderna e contemporânea sempre de modo conflitivo, numa espécie de jogo de soma zero. A segunda narrativa compreende republicanismo e liberalismo como produtos de um mesmo e diversificado movimento intelectual 
da Era moderna. Essa segunda narrativa, contudo, não é monolítica, apresentando-se em três diferentes versões: o liberalismo como uma derivação e empobrecimento do republicanismo; o liberalismo como derivação, atualização e aperfeiçoamento do republicanismo; e o republicanismo como movimento antagonista não do conjunto da tradição liberal, mas de uma vertente específica do liberalismo, inaugurado com a "invenção" da liberdade de mercado.

Dada a natureza multifacetada das grandes tradições de pensamento político, não causa surpresa o estado inconclusivo do debate historiográfico sobre as relações entre republicanismo e liberalismo. A mesma impossibilidade de fechamento do debate é observada quando passamos do campo da história das ideias para o campo da teoria política contemporânea, o que faço a seguir.

\section{Não interferência ou não dominação? A disputa no front analítico-normativo}

Em seu famoso ensaio de 1958, "Dois conceitos de liberdade", Isaiah Berlin (2002) chamava a atenção para a existência de dois modos de conceber a liberdade humana: a liberdade positiva e a liberdade negativa. Escrito em um contexto de intensa polarização ideológica, esse texto desencadeou um debate que perdura até os dias de hoje. Trata-se, provavelmente, da contribuição mais influente no debate sobre a liberdade no âmbito da teoria política de inspiração analítico-normativa (Baum e Nichols, 2013).

Mas Berlin não foi o primeiro autor liberal a usar os qualificativos "positivo" e "negativo" para referir-se aos dois conceitos de liberdade que ele enquadrava em termos dicotômicos. Outros o antecederam. Já no começo do século XX, Guido de Ruggiero, filósofo italiano de inspiração neoidealista, referia-se a duas tradições distintas do conceito, utilizando exatamente a mesma designação difundida por Berlin. Para Ruggiero (1927, p. 352), "a história apresenta- 
-nos duas concepções [de liberdade]": a primeira desenvolve-se no século XVIII e a segunda no século XIX. Ambas seriam produtos do desenvolvimento do liberalismo moderno, sendo que a liberdade negativa teria precedido cronologicamente a liberdade positiva. A principal distinção entre essas duas concepções de liberdade é a seguinte: enquanto a "liberdade negativa consistia em negar toda autoridade e toda lei, a nova liberdade positiva consistia em transferir a fonte da autoridade e da lei para o íntimo da mente humana”. Ruggiero era um dos muitos protagonistas do amplo movimento intelectual neo-hegeliano que se alastrou pela Europa nas últimas décadas do século XIX e nas primeiras do século XX, envolvendo pensadores da estatura do também italiano Benedetto Croce e dos britânicos F. H. Bradley, T. H. Green, Bernard Bosanquet (Mander, 2011; Boucher e Vincent, 2000). Ruggiero narra uma história do liberalismo moderno em que a concepção positiva de liber196 dade surge como superação dialética da concepção negativa. Esta última teria sido produto de uma era em que a questão emergencial consistia em assegurar a liberdade dos indivíduos diante dos poderes autocráticos do Estado. Com as revoluções de fins do século XVIII, e com a nova era de construção institucional que se abria, o problema passaria a ser menos o de assegurar uma esfera de não intervenção na vida privada dos indivíduos e mais o de promover os meios para o autogoverno das comunidades políticas. A passagem da liberdade negativa à liberdade positiva é assim saudada como um aperfeiçoamento da tradição liberal.

Embora a terminologia adotada por Isaiah Berlin seja idêntica à utilizada por Ruggiero, o sentido da reconstrução de Berlin é completamente oposto ao sentido que se depreende da análise do filósofo italiano. Berlin (2002, p. 237) argumenta que "as noções 'positiva' e 'negativa' de liberdade desenvolveram-se historicamente em direções divergentes [...] até entrarem por fim em conflito direto uma 
com a outra". Longe de considerar a liberdade positiva um aperfeiçoamento do liberalismo e uma superação da liberdade negativa, o autor lamenta o fato de inúmeros pensadores liberais terem sucumbido a esse tipo de entendimento da liberdade. O caso mais notável seria o de Kant, com seu entendimento da liberdade com uma forma de obediência à lei moral. Com isso, esses liberais acabariam por endossar o paradoxo contido na crença de que os homens poderiam ser obrigados à liberdade, como queria Rousseau. Escrevendo no contexto do embate político e ideológico da Guerra Fria, Berlin associa a retórica da liberdade positiva aos movimentos e regimes totalitários que assombraram o século XX. A despeito de sua indiscutível contribuição no campo analítico, subjaz à taxonomia de Berlin uma tomada de partido no campo ideológico: estaríamos mais imunes à perda da liberdade rejeitando o apelo à liberdade positiva e aderindo incondicionalmente à tese de que apenas a liberdade negativa é compatível com o pluralismo ético, cultural e político das sociedades contemporâneas.

Berlin define a liberdade negativa como a ausência de impedimento externo à ação dos indivíduos. Mais precisamente, como "a área em que o sujeito - uma pessoa ou grupo de pessoas - é ou deve ter permissão de fazer ou ser o que é capaz de fazer ou ser, sem a interferência de outras pessoas" (Berlin, 2002, p. 229). Trata-se de uma concepção de liberdade que se define analiticamente antes pela ausência do que pela presença de algo, e é precisamente por isso que ela é chamada de negativa. Já a liberdade positiva, de acordo com o autor, define-se em linhas gerais pela presença do autodomínio, que pode assumir variadas formas, desde as ideias de autorrealização de ascéticos e quietistas, até concepções de autonomia e autogoverno mais próprios do pensamento social e político. Em qualquer dessas formas, está implícita uma luta entre um "eu superior" mais próximo da razão e um "eu inferior" a ser submetido em benefício 
do alcance de uma meta específica, orientada por uma concepção particular do bem. A crença na existência de um fim último, um valor supremo para o qual todos os outros valores humanos deveriam convergir, representa um traço típico da liberdade positiva, que apresenta conteúdo determinado, em contraste com o conteúdo sempre indeterminado da liberdade negativa.

A contribuição de Berlin aos estudos sobre a liberdade desencadeou um vigoroso debate, que persiste até a atualidade (Cherniss, 2013). De um lado, estão os que aceitam, no essencial, o enquadramento analítico da teoria de Berlin, apenas tratando de inverter o sinal normativo dessa teoria. Charles Taylor, por exemplo, concorda com a ideia de que há realmente duas maneiras, ou duas "famílias" de reflexão sobre a liberdade. Modificando a terminologia de Berlin, sem no entanto modificar em profundidade seus conceitos, Taylor refere-se à liberdade como um "exercise concept", 198 equivalente à definição de liberdade positiva, e à liberdade como um "opportunity concept", equivalente à concepção negativa. Mas Taylor sugere que há certo maniqueísmo na visão de Berlin, certamente decorrente de sua sensibilidade de pluralista convicto diante do fenômeno do totalitarismo. O erro de Berlin estaria em sugerir uma inclinação "monista”, ou mesmo totalitária, a todas as variantes da concepção positiva de liberdade. Para Taylor, esse erro tem origem na formulação de Hobbes da liberdade como ausência de oposição externa ao movimento dos corpos. O problema, porém, é que

[...] a pura liberdade negativa, a definição hobbesiana, é insustentável. A liberdade não pode ser apenas a ausência de obstáculos externos, uma vez que há também obstáculos internos. E tampouco podem os obstáculos internos ser confinados apenas àqueles que o sujeito identifica enquanto tais, como se fosse seu árbitro final; 
e isso porque ele pode estar profundamente enganado sobre seu propósito e sobre o que quer repudiar (Taylor, 1985, p. 228).

De outro lado, há os teóricos da liberdade que compartilham a orientação normativa de Berlin, porém alterando a estrutura analítica de sua teoria. Dentre estes, se destacam Felix Oppenheim (1963) e Gerald McCallum $(1967)^{5}$. Ambos contestam a existência de dois conceitos de liberdade, argumentando que a liberdade é uma só ${ }^{6}$. McCallum, em particular, contribui com estabelecimento de uma fórmula para representar a estrutura lógica da liberdade. Segundo o autor, o motivo de tantas disputas e confusões no debate sobre o conceito de liberdade, além das desavenças normativas, reside na dificuldade de os teóricos entenderem a liberdade como uma "relação triádica", que envolve sempre um agente $(x)$ livre de um constrangimento $(y)$ para realizar um objetivo $(z)$. Daí a fórmula geral

5 Em artigo recente, Coser afirma que eu teria "falhado em perceber a distinção fundamental entre as concepções de McCallum e Berlin”. E isso porque, em seu entender, "a concepção de liberdade de McCallum não mostra nenhuma similaridade com a concepção de Berlin, uma vez que McCallum pressupõe a existência de um fim, enquanto Berlin rejeita, radicalmente, a ideia de que um fim é necessário à ação livre” (Coser, 2014, p. 59). Em primeiro lugar, não ignorei que McCallum "inovou em vários aspectos" ao formular sua concepção em contraposição à de Berlin (Silva, 2008, pp. 170-71). A defesa de McCallum da liberdade como um conceito único, baseado em uma relação triádica entre agentes, barreiras e fins, diferencia-se claramente da conceituação dicotômica de Berlin. O que procurei apontar é que, sem prejuízo de sua inovação analítica, McCallum filia-se à mesma orientação normativa de Berlin, nomeadamente, a orientação liberal. Em segundo lugar, parece-me no mínimo imprecisa a afirmação de que "Berlin rejeita, radicalmente, a ideia de um fim necessário à ação livre", e que isto explicaria a diferença fundamental entre a sua visão e a de McCallum. A rigor, o que Berlin rejeita é a noção de que a realização de fins determinados e com conteúdos específicos são necessários à liberdade. Daí suas objeções à liberdade positiva, a qual pressupõe a realização de valores últimos vinculados a concepções particulares do bem. Neste aspecto, não há diferença entre Berlin e McCallum. Ambos operam com a ideia de que a ação livre é sempre dirigida à realização de um fim, sem, no entanto, atribuir qualquer conteúdo particular e necessário ao fim perseguido na ação.

6 Recentemente, essa linha de análise foi também explorada e endossada por Nelson (2005). 
de McCallum: “ $x$ é (não é) livre de y para fazer (não fazer, tornar-se, não se tornar) $z$ ”. Ou seja:

Não importa o momento em que a liberdade de algum agente ou agentes esteja em questão, é sempre a liberdade em relação a algum constrangimento ou restrição a, interferência em, ou impedimento para fazer, não fazer, tornar-se, ou não se tornar algo (McCallum, 1967, p. 314).

Até meados da década de 1990, as posições acima descritas dominaram o debate sobre a liberdade. Os seguidores de Berlin assumiam a existência de dois tipos de liberdade e argumentavam em favor da liberdade negativa. Pensadores associados ao comunitarismo também aceitavam a dicotomia formulada por Berlin, mas argumentavam em favor da liberdade positiva. Por fim, teóricos como McCallum e Oppenheim rejeitavam a dicotomia, argumentando que há 200 apenas um conceito de liberdade, caracterizado por uma relação triádica entre agentes, impedimentos e fins.

A publicação de dois livros, ambos de 1997, alterou consideravelmente os termos do debate. Refiro-me a Republicanism, de Philip Pettit, e Liberty before liberalism, de Quentin Skinner. A contribuição dos republicanos neorromanos ao debate consiste na tese de que não há apenas uma, nem mesmo somente duas maneiras de se conceber a liberdade. Sem deixar de reconhecer a coerência dos discursos sobre as liberdades positiva e negativa, Pettit e Skinner desenvolvem o argumento de que a dicotomia encobre a existência histórica e a especificidade analítica de uma terceira concepção de liberdade. Conforme Pettit (1997, pp. 21-22),

[...] a taxonomia de Berlin, de liberdades positiva e negativa, afasta uma terceira possibilidade mais ou menos saliente. Ele pensa em liberdade positiva como domínio de si próprio e em liberdade negativa como ausência de 
interferência alheia. Todavia, domínio e interferência não se equivalem.

O núcleo do esquema conceitual do republicanismo neorromano é uma concepção de liberdade irredutível a qualquer dos polos da dicotomia entre liberdade negativa e liberdade positiva. Ou seja, a liberdade política não se define nem pela simples ausência de oposição externa às ações individuais, nem pela presença de qualquer variante do "domínio de si", como a participação dos cidadãos no autogoverno da cidade.

Embora a liberdade republicana defina-se também de maneira negativa, isto é, pela ausência, não pela presença de algo, o que deve estar ausente para se falar em liberdade não é a indiscriminada interferência externa nas preferências e escolhas dos indivíduos. Para os neorrepublicanos, requer-se a ausência de apenas um tipo particular de interferência, resultado da dependência e da dominação como fenômenos vinculados à existência de "poder arbitrário" de determinados agentes sobre outros. Se, na formulação dominante da liberdade negativa, qualquer tipo de interferência é visto como lesivo à liberdade, na formulação republicana, o dano à liberdade é causado somente pela interferência arbitrária. Nesse particular, a concepção republicana de liberdade negativa é mais específica do que a concepção liberal. Em outro sentido, porém, ela é mais ampla, uma vez que os liberais advogam que apenas a interferência efetiva é antagônica à liberdade, não cabendo falar em redução ou perda da liberdade, a menos que uma oposição externa impeça de fato a ação de um indivíduo.

Para os republicanos, uma das características centrais da relação de dominação é que ela permanece em vigor mesmo quando o agente dominante abstém-se de interferir efetivamente nas escolhas e ações do agente dominado. A afronta à liberdade decorre não apenas da existência efetiva da inter- 
ferência arbitrária, mas também de sua existência potencial. Tome-se o caso extremo e paradigmático da relação de dominação entre senhor e escravo, um dos principais topoi da retórica republicana desde a Antiguidade romana. $\mathrm{O}$ fato de um escravo viver sob o domínio de um senhor benevolente não faz dele menos escravo, ou seja, não o torna livre. A ausência atual de impedimentos às suas escolhas e ações é apenas um corolário de um dos estados possíveis dos desejos de seu senhor, e ele, escravo, sabe disso. A consciência desse estado de sujeição pesa inevitavelmente sobre suas atitudes, as quais tendem a assumir a forma de antecipações da vontade do senhor. $\mathrm{O}$ ponto decisivo é que não se pode considerar livre um agente cujas escolhas e atitudes realizam-se sob a influência da ansiedade decorrente da sua consciente dependência da vontade de outrem. Conforme Skinner, este ensinamento, que se encontra no núcleo da concepção de liberdade reivindicada pelos teóricos atuais do republicanismo, já se fazia presente 202 em autores republicanos do século XVII na Inglaterra.

Como James Harrington afirmaria, em 1656, na sua exposição clássica da teoria republicana, Oceana, a desgraça dos escravos é que eles não têm o controle de sua vida, estando consequentemente forçados a viver em um estado de incessante ansiedade com relação ao que lhes pode ou não acontecer (Skinner, 2010, p. 12).

A crítica mais ambiciosa dos neorromanos à teoria da liberdade negativa liberal aponta a indiferença dessa teoria aos casos de dominação sem interferência efetiva, o que, no limite, levaria a aceitação do paradoxo do "escravo livre". Uma consequência dessa crítica é a conclusão dos neorromanos de que não há um necessário trade-off entre liberdade e interferência, como sugerem os teóricos da liberdade negativa na linha de Berlin. Melhor dizendo, há determinadas formas de interferência que embora "condicionem" o exercício 
da liberdade, de modo algum "comprometem" a liberdade. Este é o caso da interferência ocasionada pelo aparato legal nas preferências e escolhas dos indivíduos, ao menos quando a lei é formulada, promulgada e aplicada segundo os princípios do republicanismo, atendo-se aos "interesses comuns assumidos" em dada comunidade. Uma legislação que cria barreiras para evitar que determinados indivíduos ou grupos de indivíduos exerçam poder arbitrário sobre outros não compromete a liberdade como não dominação, pelo contrário, a fortalece, tornando-a mais resiliente e acessível a todos.

Essas investidas dos neorromanos contra a concepção liberal de liberdade negativa têm sido objeto de intensa crítica. Há pelo menos uma década e meia, Allan Patten já chamava a atenção para a dificuldade do republicanismo de Skinner de oferecer uma alternativa eficaz ao liberalismo. Em meados da década de 1990, Patten tinha a seu dispor apenas os textos da primeira etapa da reflexão de Skinner sobre a história do conceito de liberdade, textos estes escritos ao longo da década de 1980 e dedicados ao tema da liberdade no Renascimento italiano e especialmente na obra de Maquiavel. Naquele momento, Skinner entendia a liberdade republicana de uma maneira que pouco se diferenciava teoricamente da concepção negativa hobbesiana. Referindo-se a Maquiavel, Skinner argumentava que ele "não tem objeções à constatação hobbesiana de que a capacidade de perseguir tais fins sem obstrução é o que determina a 'liberdade' propriamente dita" (Skinner, 1984, p. 217). Onde então residiria a diferença entre a concepção maquiaveliana (republicana) de liberdade e aquela defendida por Hobbes? Skinner sustentava que Maquiavel

[...] apenas argumenta que o desempenho de serviços públicos e o cultivo de virtudes necessárias para desempenhá-los provam, sob exame, serem instrumentalmente necessários para evitar a coerção e a servidão, logo sendo condições necessárias para 
assegurar qualquer nível de liberdade pessoal no sentido hobbesiano, ordinário, do termo (Skinner, 1984, p. 217).

Era a esse "republicanismo instrumental" de Skinner que Patten se referia em sua crítica, que segue basicamente o seguinte raciocínio: nos pontos em que o republicanismo instrumental acerta, ele é perfeitamente compatível com o liberalismo igualitário de autores como Ralws e Dworkin; nos pontos em que se distingue do liberalismo, ele segue por caminhos pouco promissores, que os liberais deveriam a todo custo evitar. Assim,

[... ] a formulação de Skinner do republicanismo instrumental não representa uma melhoria das atitudes liberais em relação à cidadania e à virtude cívica, uma vez que ela falha em identificar qualquer desacordo filosoficamente interessante entre as duas posições (Patten, 1996, p. 36).

No entanto, para efeitos de avaliação do estado atual do debate entre republicanos e liberais, a crítica de Patten apresenta um sério limite. Ela se concentra nos estudos iniciais de Skinner, que reformulou amplamente sua visão sobre a liberdade a partir de meados da década de 1990. Duas circunstâncias contribuíram para tal reformulação. A primeira foi o deslocamento da atenção do historiador de Cambridge do contexto do Renascimento italiano para o contexto das disputas entre o parlamento e a coroa no século XVII inglês. Os textos de Maquiavel cedem lugar aos textos de autores como Harrington, Milton, Sidney e outros, que Skinner passou a identificar como comprometidos com uma concepção "neorromana" de liberdade ${ }^{7}$. A segunda circunstância foi o

\footnotetext{
7 Para um apanhado dessa mudança de contexto histórico como objeto da investigação de Skinner sobre a liberdade, ver Palonen (1998). Registre-se que Palonen lamenta esse movimento de Skinner, o qual teria resultado em concessões indevidas ao liberalismo contratualista de nossa época.
} 
início da interlocução de Skinner com Pettit (Silva, 2008). Tomando como ponto de partida a contribuição historiográfica de Skinner, Pettit elevou o conceito republicano de liberdade a um patamar superior de refinamento analítico, resolvendo dificuldades presentes nos textos iniciais do historiador. Se em Liberdade antes do liberalismo, Skinner dá um importante passo na direção da concepção da liberdade republicana articulada por Pettit, em seus estudos mais recentes, ele passa a adotar integralmente a essência dessa concepção (Skinner, 2008, 2010).

Ainda que a crítica de Patten ao "republicanismo instrumental” tenha perdido sua eficácia, uma geração mais recente de críticos liberais toma como alvo exatamente a versão atual da liberdade republicana. Dentre esses críticos merecem destaque dois defensores do que se convencionou chamar de teoria da "liberdade negativa pura". Em seus alentados estudos sobre o conceito de liberdade, Ian Carter (1999) e Mathew Kramer (2003) procuram restabelecer a posição dos liberais no debate analítico sobre a liberdade, ao mesmo tempo que invectivam contra a singularidade e a suposta superioridade da alternativa republicana ${ }^{8}$.

Carter parte do conceito de "liberdade total" (overall freedom) para desenvolver uma sofisticada teoria sobre a mensurabilidade da liberdade. A liberdade total de uma pessoa resulta de uma combinação entre conjuntos de liberdades específicas acessíveis em certo instante, bem como ao longo do tempo. Assim, quando se considera determinado constrangimento a um conjunto de liberdades específicas, deve-se avaliar em que medida outros conjuntos de liberdades específicas podem tornar-se mais (ou menos) acessíveis tanto no momento do constrangimento como em momento futuro. Carter sustenta que, assim como os liberais, os republicanos têm em mente a noção

\footnotetext{
8 Carter e Kramer desenvolvem suas teorias sob forte influência de Hillel Steiner (1994). Os três autores colaboraram sistematicamente, tendo editado em conjunto uma extensa antologia sobre o conceito de liberdade (Steiner, Carter \& Kramer, 2007).
} 
de liberdade total. Mas os liberais teriam a vantagem de prescindirem do apoio de uma visão normativa de liberdade. Por isso, Carter prefere enquadrar a liberdade republicana a partir de uma expressão anterior de Pettit, que identificava a liberdade como "não interferência resiliente" (Pettit, 1993, p. 17). Se a concepção republicana refere-se à liberdade total em termos de não interferência resiliente, "o mais que se pode atribuir a Skinner e Pettit é um conjunto útil de hipóteses empíricas (que apontam para certos conjuntos de arranjos institucionais) sobre como maximizar a liberdade", afirma Carter. Desse modo, continua o autor, os neorrepublicanos teriam pouco a apresentar como novidade, já que "a diferença entre republicanos e liberais é empírica em vez de conceitual, e a suposta diferença sobre o significado dos 'constrangimentos à liberdade' é uma ilusão” (Carter, 1999, p. 239).

Carter explicita corretamente os dois principais enunciados da teoria da liberdade como não dominação: (1) 206 uma pessoa pode ter sua liberdade reduzida sem sofrer qualquer interferência efetiva; (2) uma pessoa pode sofrer interferência efetiva sem que se reduza sua liberdade. Ele também afirma que a comparação entre a liberdade republicana e a liberdade negativa liberal deve ser aceita somente em relação ao primeiro enunciado, devendo ser o segundo enunciado rejeitado por duas razões.

A primeira é de ordem intuitiva, já que parece suficientemente claro que o impedimento da ação de um indivíduo corresponde a uma limitação da liberdade de ação desse mesmo indivíduo, ainda que a interferência ocorra em sintonia com o interesse do indivíduo que a sofre, ou seja, quando ela ocorre isenta de arbitrariedade.

A segunda razão é de ordem epistemológica, pois diz respeito ao que se espera de uma teoria da liberdade negativa no plano cognitivo. Carter sustenta que a tese de que pode haver interferência sem perda da liberdade deve ser rejeitada porque decorre de uma moralização do conceito de liberdade. 
Uma concepção moralizada de liberdade admite que "obstáculos não restringem a liberdade de alguém na medida em que sejam obstáculos moralmente legítimos" (Carter, 2008, p. 65). Carter cita uma passagem em que Pettit chega mesmo a sugerir que "nem uma cobrança de impostos nem uma ordem de prisão precisam retirar da liberdade de alguém" (Pettit, 1997, p. 65). Para Carter, contudo, ainda que uma ordem de prisão seja aplicada com justiça a um réu confesso, no mais genuíno interesse da coletividade, tende ao absurdo a proposição de que o aprisionamento não retira a liberdade do prisioneiro ${ }^{9}$. Neste caso, certamente haverá conflitos entre o interesse individual e o interesse comum. Carter (2008, p. 65) argumenta que

[...] onde tais conflitos ocorrem, não vejo qualquer razão para privilegiar os interesses comuns em detrimento do interesse pessoal do agente em decidir quais obstáculos contam como casos de ausência de liberdade, a menos que tal razão consista em um ponto de vista moral.

Rejeitando como contraintuitiva e moralizante a proposição de que uma interferência não arbitrária não afeta desfavoravelmente a liberdade, Carter, por outro lado, reconhece algum sentido, embora sob fortes reservas, na primeira proposição de Pettit, segundo a qual pode haver perda da liberdade sem a ocorrência de uma efetiva interferência. Carter entende que Skinner e Pettit sustentam que o medo e a ansiedade, inibidores da ação dos agentes dominados diante do poder arbitrário dos dominantes, podem atuar como forças redutoras da liberdade. Mas retruca que essa possibilidade em nada surpreenderia os defensores contemporâneos da liberdade negativa pura, cuja teoria estaria perfeitamente equipada para lidar com essa constatação. E aqui reside o desafio central de

\footnotetext{
9 Sobre a importância do paradigma do prisioneiro como um teste alegadamente insuportável à liberdade republicana, ver Wendt (2011).
} 
Carter aos teóricos neorromanos: ao contrário do que estes sugerem, a teoria da liberdade negativa seria perfeitamente capaz de incorporar os fenômenos da dominação e da dependência como barreiras à liberdade individual.

Construindo uma teoria da liberdade em sintonia fina com Carter, Matthew Kramer (2003, p. 149) acredita que "quando sutilezas e distinções finas são devidamente levadas em conta, os expoentes modernos da liberdade negativa podem sair-se muito bem na confrontação - e na reconciliação - com suas contrapartes cívico-republicanas”. Uma das dificuldades apontadas por Kramer na crítica dos republicanos à liberdade negativa é que raramente essa crítica se dirige a teóricos liberais contemporâneos. Excetuando-se as referências ocasionais a Isaiah Berlin - o grande alvo dos republicanos não é um autor liberal, tampouco contemporâneo. Trata-se de Thomas Hobbes, cuja concepção de liberdade como ausência de impedimento externo ao movimento, 208 objeto do capítulo XXI do Leviatã, parece resumir a visão da liberdade que Skinner e Pettit julgam encontrar no coração do liberalismo contemporâneo (Skinner, 2010; Pettit, 2005).

Kramer insiste que, não obstante o indiscutível valor analítico da concepção hobbesiana de liberdade, os teóricos contemporâneos da liberdade negativa afastam-se de Hobbes em ao menos dois aspectos cruciais. Em primeiro lugar, os teóricos contemporâneos restringem o campo de aplicação do conceito hobbesiano. Enquanto Hobbes considera que a liberdade em sua "significação própria" aplica-se tanto a pessoas quanto a outros animais e mesmo a objetos inanimados, teóricos como Berlin, Carter e Kramer consideram que ela se aplica apenas à relação entre pessoas. Nesse sentido, a liberdade negativa é essencialmente social. Além disso, embora continuem a postular a natureza não normativa da liberdade negativa, os teóricos contemporâneos descartam a cláusula restritiva mediante a qual Hobbes afirmava que apenas barreiras físicas externas ao corpo em movimento são capazes de 
retirar desse corpo a liberdade de se mover. Ao descartarem essa restrição desnecessária, os teóricos da liberdade negativa pura preparam sua teoria para lidar com os efeitos corrosivos da liberdade decorrentes do fenômeno da dominação.

Para Kramer, os republicanos acreditam que a dominação se realiza pela ação de fatores psicológicos como a ansiedade e o medo dos dominados quando estes são de algum modo conscientes da situação de submissão em que se encontram em relação ao agente dominante. Mas por que, afinal, ele pergunta, a teoria da liberdade negativa pura estaria impossibilitada de reconhecer este efeito restritivo sobre a liberdade causado pela relação de dominação? Os novos teóricos da liberdade negativa não veem razão alguma para tal, uma vez que sejam consideradas não somente as liberdades específicas do indivíduo no momento presente da ameaça de interferência do agente dominante, mas também sua liberdade total a ser desfrutada em momento futuro, quando da efetivação da interferência retaliatória. Segundo Kramer, a crítica dos neorromanos à liberdade negativa falha em reconhecer que a liberdade total de uma pessoa é "amplamente determinada pelo leque de combinações de liberdades conjuntivamente exercíveis a ela disponíveis”. Uma vez reconhecida essa fórmula, seria forçoso notar que a liberdade total de uma pessoa subordinada é reduzida quando essa pessoa "tem de recorrer a obsequiosidade [...] de modo a evitar as medidas punitivas da pessoa dominante" (Kramer, 2008, p. 44). Ao contrário do que acreditam os neorromanos, longe de se tratar de uma situação em que a interferência não é exercida, trata-se de uma situação em que ela se exerce amplamente. Em resumo, segundo Kramer (2008, p. 44):

[...] sob qualquer visão defensável da liberdade negativa, devemos concluir que a liberdade total de uma pessoa "P" é substancialmente reduzida com sua sujeição à parte dominante. Contrariamente ao que Pettit sustenta, o domínio dessa parte está realmente sendo exercido - não pela 
perpetração efetiva da violência, mas pela pronta disposição da parte dominante em exercer a violência. Essa disposição por si mesma elimina muitas combinações de liberdades conjuntivamente exercíveis por "P".

Skinner e Pettit, posicionando-se em relação às críticas de Carter e Kramer, reafirmam o caráter distintivo da concepção republicana de liberdade negativa. Pettit salienta que os novos teóricos da liberdade negativa pura julgam que "a liberdade de escolha não é afetada por nada além da remoção de uma opção". Eles acreditam que "eu interfiro em você e causo impacto em sua liberdade somente quando eu impeço você de fazer algo" (Pettit, 2008, p. 119). Para esses teóricos, o fato de uma pessoa encontrar-se sob o domínio de outra só conta como redução da liberdade porque a dominação consiste numa interferência efetiva que remove opções que o agente dominado, de outro modo, 210 teria a seu dispor. O agente dominado tende a comportar-se de modo subserviente porque ele reconhece como credível a ameaça de sanção perpetrada pelo agente dominante, pronto a atuar caso o comportamento do dominado não seja suficientemente humilde e servil. Seria, portanto, o temor da punição do comportamento audacioso que faria com que o agente dominado removesse de seu leque de opções conjuntivamente exercíveis aquelas que poderiam despertar a ira punitiva do agente dominante.

Pettit e Skinner argumentam que essa tentativa de apresentar o fenômeno da dominação como uma interferência efetiva nas escolhas dos dominados tende a perder de vista um aspecto fundamental da concepção de liberdade como não dominação. Os teóricos da liberdade negativa continuam a ignorar o fato de que a dominação é um fenômeno que pode ocorrer com ou sem uma interferência efetiva. Nos termos de Pettit, sempre que uma pessoa realizar suas escolhas sob a sombra de um "controle alienado", sua liberdade 
estará comprometida. E isso vale para o caso do controle em questão jamais exercer-se de fato. Mais: ainda que o agente dominante seja, por sua própria índole, do tipo indisposto a interferir, e ainda que a "probabilidade" de ele desejar bloquear as ações do dominado seja de fato muito reduzida, a simples presença de um poder sem controle é razão suficiente para a perda da liberdade do agente dominado. Conforme Pettit, mesmo

[...] uma redução na probabilidade de interferência nas mãos de um controlador externo não removerá o espectro do poder alienado [...] Esse mal impessoal é mais ou menos insensível à probabilidade de interferência endogenamente sustentada; o poder alienado permanecerá ativo na medida em que o agente pode ou não interferir, sejam quais forem as probabilidades reduzidas de interferência ditadas pela natureza do agente (Pettit, 2008, p. 124).

Portanto, a presença do poder arbitrário tipifica qualitativamente a relação de dominação, não quantitativamente. Carter e Kramer entendem que a liberdade negativa não é afetada em uma situação em que o exercício efetivo da interferência arbitrária é pouco provável. Para os republicanos, porém, essa formulação probabilística acerca dos malefícios da relação de dominação perde de vista o essencial. Seja qual for o grau de probabilidade do exercício efetivo da interferência arbitrária, a liberdade como não dominação continua determinada pela participação em um status. Trata-se da posição assumida por um agente, em relação a outros, no contexto das normas e instituições vigentes em determinada sociedade. Em certo sentido, trata-se de uma questão de tudo ou nada, pois o agente simplesmente detém ou não detém o status de pessoa livre. Se ele o detém, poderá sempre olhar nos olhos de seus concidadãos em situação de igualdade, sem receios e sem motivos para o comportamento obsequioso ou servil. Independentemente 
de qualquer preocupação com a probabilidade da interferência arbitrária, ele passará no que Pettit define alusivamente como o "teste dos olhos nos olhos" (eyeball test) ${ }^{10}$.

Assim como a perda da liberdade implícita na relação de dominação não depende do grau de probabilidade do exercício do poder arbitrário do agente dominante, ela também não depende do tipo particular de atitude levada a efeito pelo agente dominado. Carter e Kramer haviam argumentado que a interferência efetiva resultante da relação de dominação é um efeito antes das atitudes do dominado do que do dominante. Tendo consciência da situação subordinada em que se encontra, o agente dominado sabe exatamente o que fazer para evitar a ira de seu mestre: comportar-se de modo suficientemente humilde e servil. É este tipo de comportamento que lhe retira opções que de outro modo poderia exercer, reduzindo assim sua liberdade total. Skinner objeta essa conclusão, indicando que ela decor212 re de mais uma incompreensão dos teóricos da liberdade negativa sobre a liberdade republicana. Mobilizando uma vez mais o topos da tradição republicana do escravo como tipo puro de agente dominado, Skinner esclarece que "o que basicamente distingue a vida dos escravos de acordo com a tradição republicana é o fato de eles serem condenados a uma vida de completa incerteza. Eles jamais sabem o que pode ou não lhes acontecer. Mas se esta consideração os leva, o que provavelmente acontece, a agir com a servilidade que deles se espera, não é porque eles serão indevidamente obstruídos ou penalizados caso tentem agir de outra maneira. Antes, será porque, em consequência de seu senso

\footnotetext{
${ }^{10}$ Conforme esclarece o autor, "o teste dos olhos nos olhos requer que as pessoas sejam capacitadas e protegidas para as escolhas básicas de suas vidas - em suma, para as liberdades básicas - de modo que elas possam olhar os outros nos olhos sem motivos para o medo ou a deferência que o poder de interferência pode inspirar. Quando você desfruta de segurança social, médica e judicial, e é beneficiada por uma ordem legal e econômica apropriada, você não depende para sua segurança da indulgência ou condescendência de outros" (Pettit, 2014, p. xxxvi).
} 
básico de incerteza, eles sentem uma compreensível disposição de atuar com segurança” (Skinner, 2008, p. 98).

Em suma, para os neorromanos, a incerteza e insegurança do escravo, determinada pela vulnerabilidade de seu status social e jurídico, constitui a essência supressora de sua liberdade. O juízo subjetivo do escravo sobre o grau de probabilidade da ocorrência de interferência arbitrária (e retaliatória) futura em suas vidas guarda uma relação apenas contingente com o fenômeno da dominação.

Seja qual for a inclinação normativa de quem se depara com o debate corrente sobre a liberdade na teoria política, a conclusão que se impõe é a de que ele permanece aberto. A preferência por uma ou outra visão da liberdade não apaga os méritos das visões concorrentes. No caso da disputa entre republicanos e liberais, a questão central, refratária à resolução final, é saber se a liberdade é um atributo das escolhas ou um atributo das pessoas. Intuitivamente, não parece haver dificuldades para se falar em "escolhas livres", como querem os liberais, por um lado, ou em "pessoa livre", como querem os republicanos, por outro.

\section{Ricardo Silva}

é professor do Departamento de Sociologia e Ciência Política da Universidade Federal de Santa Catarina (UFSC) e pesquisador do $\mathrm{CNPq}$.

\section{Bibliografia}

BAUM, B.; NICHOLS, R. (eds.) 2013. Isaiah Berlin and the politics of freedom. London: Routledge.

BAYLIN, B. 1967. The ideological origins of the American Revolution.

Cambridge, Mass.: Harvard University Press.

BERLIN, I. 2002. "Dois conceitos de liberdade". In: HARDY, H.;

HAUSHEER, R. (orgs.). Isaiah Berlin: estudos sobre a humanidade. São

Paulo: Companhia das Letras.

BOUCHER, D.; VINCENT, A. 2000. British idealism and political theory.

Edinburgh: Edinburgh University Press. 
CARTER, I. 1999. A measure of freedom. Oxford: Oxford University Press. . 2008. "How are power and unfreedom related". In: LABORDE, C.;

MAYNOR, J. (eds.). Republicanism and political theory. London: Blackwell.

CHERNISS, J. 2013. A mind and its time: the development of Isaiah Berlin's political thought. Oxford: Oxford University Press.

COSER, I. 2014. "The concept of liberty: the polemic between neorepublicans and Isaiah Berlin”. Brazilian Political Science Review, v. 8, n. 3.

GALLIE, W. 1956. "Essentially contested concepts". Proceedings of Aristotelian Society, n. 56.

HARTZ, L. 1955. The liberal tradition in America. New York: Harcourt. KALYVAS, A.; KATZNELSON, Ira. 2008. Liberal beginnings: making a republic for the moderns. Cambridge: Cambridge University Press.

KRAMER, M. 2003. The quality of freedom. Oxford: Oxford University Press. 2008. "Liberty and domination". In: LABORDE, C.; MAYNOR, J. (eds.). Republicanism and political theory, London: Blackwell.

MACGILVRAY, E. 2011. The invention of market freedom. Cambridge: Cambridge University Press.

MANDER, W. J. 2011. British idealism: a history. Oxford: Oxford University Press.

MCCALUM, G. 1967. "Negative and positive freedom”. The Philosophical Review, v. LXXVI, n. 3.

NELSON, E. 2005. “Liberty: one concept too many?”. Political Theory, v. 33, n. 1 .

NIETZCHE, F. 1998. Genealogia da moral. Trad. Paulo César Souza. São Paulo: Companhia das Letras.

OPPENHEIM, F. 1963. Dimensions of freedom. New York: St. Martin's Press.

PALONEN, K. 1998. "Liberty is too precious a concept to be left to the liberals". Finnish Yearbook of Political Thought, n. 2, pp. 243-60.

PATTEN, A. 1996. "The republican critique of liberalism". British Journal of Political Science, v. 26, n. 1.

PETTIT, Philip. 1993. "Negative liberty, liberal and republican”. European Journal of Philosophy, n. 1. 1997. Republicanism: a theory of freedom and government. Oxford: Oxford University Press. . 2005. "Liberty and Leviathan". Philosophy, Politics, and Economics, v. 4, n. 1. 2008. "Republican freedom: three axioms, four theorems". In:

LABORDE, C.; MAYNOR, J. (eds.). Republicanism and political theory, London: Blackwell. 2014. Just freedom: a moral compass for a complex world. New York: W. W. Norton and Company. 
POCOCK, J. 1975. The machiavellian moment: florentine political thought and the Antlantic Republican tradition. Princeton, NJ: Princeton University Press. 2003. "Virtudes, direitos e maneiras". In: . Linguagens do ideário político. São Paulo: Edusp.

RODGERS, D. 1992. "Republicanism: the career of a concept". The Journal of American History, v. 79, n. 1.

RUGGIERO, G. 1927. The history of European liberalism. Oxford: Oxford University Press.

SILVA, R. 2008. "Liberdade e lei no neo-republicanismo de Skinner e Pettit”. Lua Nova, n. 74. . 2012. "Teoria política, história conceitual e conceitos essencialmente contestados". In: OSTRENSKY, E.; TIERNO, P. (orgs.). Teoria, discurso e ação política. São Paulo: Alameda.

SKINNER, Q. 1978. The foundations of modern political thought. Cambridge:

Cambridge University Press. 2v. . 1984. "The idea of negative liberty: philosophical and historical perspectives”. In: SKINNER, Q; RORTY, R.; SCHNEGWIND, J. B.

(eds.). Philosophy in history. Cambridge: Cambridge University Press. . 1999. A liberdade antes do liberalismo. São Paulo: Ed. Unesp. 2002. Renaissance virtues. Cambridge: Cambridge University Press

(Visions of politics, v. 2). . 2008. "Freedom as the absence of arbitrary power". In: LABORDE, Cecile; MAYNOR, John (eds.). Republicanism and political theory.

London: Blackwell. 2010. Hobbes e a liberdade republicana. São Paulo: Cia. das Letras.

STEINER, H. 1994. An essay on rights. Oxford: Blackwell.

STEINER, H.; CARTER, I.; KRAMER, M. (eds.) 2007. Freedom: a philosophical anthology. Oxford: Blackwell.

TAYLOR, C. 1985. "What's wrong with negative liberty". In:

Philosophy and human sciences. Cambridge: Cambridge University Press.

VIROLI, M. 2002. Republicanism. New York: Hill and Wang.

WENDT, F. 2011. "Slaves, prisoners and republican freedom". Res Publica, v. 17 , n. 2.

WALKER, W. 2006. "Sallust and Skinner on civil liberty". European Journal of Political Theory, v. 5 n. 3.

WOOD, G. 1969. The creation of the American Republic, 1776-1787. Chapel Hill: University of North Carolina Press. 


\section{VISÕES DA LIBERDADE: REPUBLICANISMO E LIBERALISMO NO DEBATE TEÓRICO CONTEMPORÂNEO}

RICARDO SILVA

Resumo: Nas últimas décadas, tem-se observado um esforço de reconstituição de uma vertente do republicanismo cuja gênese remonta aos ideais e instituições da antiga República romana. Reconstruído por historiadores do pensamento político - e recentemente absorvido por teóricos de orientação analítica e normativa -, o "republicanismo neorromano" gira em torno de uma visão da liberdade como não dominação, alegadamente distinta da concepção de liberdade como não interferência, predominante no liberalismo contemporâneo. Compreendendo a liberdade como um "conceito essencialmente contestado", o artigo procura responder as seguintes questões: (1) Em que medida é defensável a tese dos neorromanos sobre rivalidade entre republicanismo e liberalismo enquanto tradições históricas singulares de pensamento político?, (2) Quais são as principais distinções conceituais entre a liberdade como não dominação e a liberdade como não interferência? Enquanto a primeira questão enquadra o debate sobre a liberdade do ponto de vista da história das ideias, a segunda o faz a partir de uma perspectiva analítica e normativa.

Palavras-chave: Republicanismo Neorromano; Liberalismo; Liberdade; Não dominação; Não Interferência.

\section{VISIONS OF LIBERTY: REPUBLICANISM AND LIBERALISM IN THE CURRENT THEORETICAL DEBATE}

Abstract: In recent decades, there has been a recovery of a strand of republicanism whose genesis dates back to the ideals and institutions of the ancient Roman Republic. Reconstructed by historians of political thought - and recently absorbed by theorists 
of analytical and normative persuasion - the "neo-Roman republicanism" revolves around a conception of freedom as nondomination, allegedly distinct from freedom as noninterference, predominant in contemporary liberalism. By understanding freedom as an "essentially contested concept", the article tries to answer the following questions: (1) To what extent is defensible the thesis (put forward by neo-Roman scholars) about the rivalry between republicanism and liberalism as single historical traditions of political thought? (2) What are the main conceptual distinctions between freedom as non-domination and freedom as noninterference? While the first question frames the debate on liberty from the point of view of the history of ideas, the second one does so from the normative and analytical perspectives.

Keywords: Neo-Roman Republicanism; Liberalism; Liberty; Nondomination; Noninterference.

Recebido: 12/12/2013 Aprovado: 07/07/2014 